\title{
Cerebral Responses to Maternal Cocaine Injection in Immature Fetal Sheep
}

\author{
CHRISTINE A. GLEASON AND RICHARD J. TRAYSTMAN \\ Departments of Pediatrics (Eudowood Neonatal Pulmonary Division), Anesthesiology/Critical Care \\ Medicine, and Gynecology and Obstetrics, The Johns Hopkins University School of Medicine, Baltimore, \\ Maryland 21287-3200
} \begin{abstract}
Previous studies in near-term sheep have shown that maternal
cocaine injection causes acute fetal cerebral vasodilation along with transient hypoxemia and hypertension. Preterm sheep fetuses have lower cerebral $\mathrm{O}_{2}$ consumption $\left(\mathrm{CMRO}_{2}\right)$ and their cerebrovascular responses to hypoxemia are attenuated compared with near-term fetuses. We therefore tested the hypothesis that fetal cerebrovascular responses to maternal cocaine injection may also differ earlier in gestation. We studied nine immature fetal sheep at 0.65 gestation using the same experimental protocol we used in previous studies in near-term sheep. Fetal studies were done in utero, $2 \mathrm{~d}$ after vascular catheter placement. We measured cerebral blood fiow (CBF) using microspheres, arterial and sagittal sinus $\mathrm{O}_{2}$ content, and cocaine concentrations. We calculated cerebrovascular resistance (CVR) as mean arterial blood pressure $\div$ CBF. Measurements were made before and 2, 5 , and $15 \mathrm{~min}$ after a $2 \mathrm{mg} / \mathrm{kg}$ maternal cocaine injection. At 2 min, fetal $\mathrm{CaO}_{2}$ decreased $(18 \pm 6 \%$, mean $\pm \mathrm{SEM})$, and there was cerebral vasoconstriction (CVR increased by $22 \pm 5 \%$ ). At
\end{abstract}

5 min, CBF increased (19 $\pm 9 \%$ ), but because blood pressure increased also, CVR returned to baseline, and therefore there was no vasodilation compared with baseline. Furthermore, at $5 \mathrm{~min}$ there was a $22 \pm 6 \%$ decrease in $\mathrm{CaO}_{2}$ and a $21 \pm 6 \%$ increase in mean arterial blood pressure. There were no changes in $\mathrm{CMRO}_{2}$ throughout the study, but at $2 \mathrm{~min}$, cerebral $\mathrm{O}_{2}$ delivery decreased. Differences in cerebrovascular responses to maternal cocaine injection earlier in gestation may be due to differences in vascular development and/or to developmental differences in responses to cocaine, cocaine metabolites, and/or to hypoxemia. (Pediatr Res 38: 943-948, 1995)

CBF, cerebral blood flow

Abbreviations

$\mathrm{CMRo}_{2}$, cerebral oxygen consumption

CVR, cerebrovascular resistance

$\mathrm{CaO}_{2}$, arterial oxygen content

MAP, mean arterial blood pressure
Cocaine abuse by pregnant women continues to be a major sociologic and medical problem in the United States $(1,2)$. Because cocaine can cause serious neurologic problems in adults, concern has been raised regarding the effects of maternal cocaine abuse on the developing brain. Although a characteristic pattern of neonatal neurologic injury and abnormal neurodevelopmental outcome has not yet emerged, clinical studies have reported an association of maternal cocaine abuse with fetal and neonatal neurologic injuries, including cerebral hemorrhages and infarctions, neurobehavioral abnormalities, and small head size (3-6). However, the pathogenesis of these defects as well as cocaine's more subtle effects on neurodevelopment is poorly understood.

Neurophysiologic studies in developing sheep, pigs, and cats have yielded conflicting results regarding the cerebrovascular

Received September 7, 1994; accepted July 7, 1995

Correspondence and reprint requests: Christine A. Gleason, M.D., Division of Neonatology, The Johns Hopkins Hospital, CMSC 210, 600 N. Wolfe St., Baltimore, MD 21287-3200.

Supported by National Institute on Drug Abuse Grant 06658 and, in part, by the Hospital for the Consumptives of Maryland (Eudowood). effects of cocaine (7-13). We previously reported cerebral vasodilation (in some brain regions) along with hypertension and hypoxemia in near-term fetal sheep, $5 \mathrm{~min}$ after a $2 \mathrm{mg} / \mathrm{kg}$ maternal cocaine injection (12), and we have also reported cerebral vasodilation despite less hypoxemia after a direct fetal cocaine injection near term (14). However, there is little or no information regarding the cerebrovascular effects of cocaine on the more immature brain.

Previous studies have demonstrated that immature fetal sheep have lower $\mathrm{CBF}$ and $\mathrm{CMRO}_{2}$ and blunted responses to hypoxemia compared with near-term fetal sheep $(15,16,40)$. We hypothesized that in preterm fetuses, cerebrovascular responses to maternal cocaine could be attenuated either because of incomplete vascular development or because of blunted responses to hypoxemia. The preterm fetal brain is of considerable clinical interest because maternal cocaine abuse is associated with a higher risk of preterm labor and low birth weight (17) as well as uteroplacental abnormalities including both chronic and acute abruptio placenta with consequent fetal or perinatal asphyxia $(18-20)$. Discovery of maturity- 
dependent fetal vascular effects of maternal cocaine abuse could account, in part, for the conflicting results in different species.

\section{METHODS}

Subjects. Nine mixed-breed fetal sheep were obtained from time-dated pregnancies verified by abdominal ultrasound. The fetuses ranged from 92 to $94 \mathrm{~d}$ of gestation (term $=145-150$ d) at the time of study (mean $93 \pm 1$ d) and weighed $832 \pm 29$ g. Three of the fetuses were one of twins and four were females. All surgical and experimental procedures were approved by our institutional Animal Care and Use Committee.

Surgical preparation. One day before surgery, food was withheld from the ewe, although she was allowed free access to water. On the day of surgery, the ewe was anesthetized with halothane (1-2\%) and an i.v. infusion of 5\% dextrose in $0.45 \%$ $\mathrm{NaCl}$ was begun via a catheter placed percutaneously in the jugular vein. A catheter was placed in the maternal abdominal aorta via the femoral artery. The uterus was exposed through a midline abdominal incision. Small uterine incisions were used to gain access to the fetus, and catheters were placed into the superior sagittal sinus, brachiocephalic trunk (via axillary arteries), and inferior vena cava (via pedal veins) by previously described methods (15). All vascular catheters were flushed and filled with heparin $(100 \mathrm{U} / \mathrm{mL})$. Uterine and abdominal incisions were closed, and all catheters were exteriorized through the ewe's flank. Ampicillin (500 mg) was instilled into the amniotic cavity through a catheter (Tygon tubing) placed there at the end of surgery. Benzathine and procaine penicillin (1 $200000 \mathrm{U})$ were administered intramuscularly to the ewe just before surgery. The ewe was fed a standard diet of hay and water and allowed a 48 -h recovery period before physiologic studies of the fetus in utero.

Physiological measurements. Blood flow was measured with the radiolabeled microsphere technique and the leastsquares method of differential spectroscopy (21). Approximately 800000 microspheres $(0.3 \mathrm{~mL})$ labeled with ${ }^{153} \mathrm{Gd}$, ${ }^{114} \mathrm{In},{ }^{113} \mathrm{Sn},{ }^{103} \mathrm{Ru},{ }^{95} \mathrm{Nb}$, or ${ }^{46} \mathrm{Sc}$ (DuPont NEN, Boston, MA) were injected over $0.5 \mathrm{~min}$ into the inferior vena cava, followed by $2 \mathrm{~mL}$ of fetal blood. Reference blood samples were withdrawn from the axillary artery at a rate of $1.03 \mathrm{~mL} / \mathrm{min}$, beginning $30 \mathrm{~s}$ before the microsphere injection and continuing for 1.0 min after the injection was completed. After completion of the study, the ewe was killed with an overdose of pentobarbital sodium followed by saturated $\mathrm{KCl}$ solution. The fetus was removed and weighed, and then the brain was immediately removed at the base and divided at the cephalic border of the pons. All supratentorial tissue (including cerebral hemispheres and midbrain) was pooled and counted to determine CBF. The cerebellum was counted separately as was the brainstem (pons and medulla). The radioactivity in all samples was determined by using a multichannel gamma-counter (Packard Instrument, Downers Grove, IL). All reference and tissue samples contained $>400$ microspheres.

Blood samples for $\mathrm{pH}$, respiratory blood gases, $\mathrm{Hb}$ concentration, and $\mathrm{O}_{2}$ saturation were anaerobically withdrawn into heparinized Natelson glass pipettes. Respiratory blood gases and $\mathrm{pH}$ were measured at $39.5^{\circ} \mathrm{C}$ using the Radiometer $\mathrm{ABL}$ 30 (Radiometer, Copenhagen, Denmark). $\mathrm{O}_{2}$ saturation and $\mathrm{Hb}$ concentration were measured with the OSM-3 Hemoximeter.

Arterial blood pressure (referenced to amniotic fluid pressure) and heart rate were continuously monitored (Gould Instruments, Oxnard, CA).

Whole blood $(2 \mathrm{~mL})$ for cocaine and its metabolites was collected in nonheparinized syringes and immediately placed into tubes containing $0.1 \mathrm{~mL}$ of enzyme inhibitor (equal parts of a saturated sodium fluoride solution and a $10 \% \mathrm{vol} / \mathrm{vol}$ solution of glacial acetic acid). The blood was mixed with the inhibitor, centrifuged, and the plasma stored frozen $\left(-70^{\circ} \mathrm{C}\right)$ until analyzed.

Cocaine, ecgonine methyl ester, and benzoylecgonine were isolated using solid-phase extraction as described by Cone et al. (22). Extraction cartridges (Worldwide Monitoring Corporation, ZSDAU020) were conditioned sequentially with methanol, water, and $\mathrm{pH} 4$ acetate buffer. Samples were diluted with deionized water and $\mathrm{pH} 4$ acetate buffer, vortexed, centrifuged, and added to the cartridges. The cartridges were washed with water, $0.1 \mathrm{~N} \mathrm{HCl}$, and methanol. The cartridges were dried under vacuum and treated with the elution solvent (methylene chloride/isopropanol/ammonium hydroxide, $80: 20: 2 \% \mathrm{vol} /$ vol). The extracts were evaporated under argon and reacted with bis(trimethylsilyl)trifluoracetamide $+1 \%$ trimethylchlorosilane in acetonitrile. The gas chromatography/mass spectrometry analyses were performed with an HP 5890A Series II gas chromatograph and 7673A automatic liquid sampler interfaced with an HP 5971A mass selective detector operated in the selected ion monitoring mode.

Experimental protocol. On the day of study, the ewe was brought into the laboratory and placed in a specially designed study cart with free access to food. The ewe was allowed at least $1 \mathrm{~h}$ to become accustomed to her surroundings. During this time, $10 \mathrm{~mL}$ of maternal blood was withdrawn from the femoral artery catheter and infused into the fetal inferior vena cava while $10 \mathrm{~mL}$ of fetal blood was slowly withdrawn from the fetal axillary artery. This exchange procedure provided blood for replacement during the study without significant changes in the fetal $\mathrm{PO}_{2}$ at which $\mathrm{Hb}$ is one-half saturated with $\mathrm{O}_{2}\left(\mathrm{P}_{50}\right)$ which may be expected with direct transfusion of maternal blood. A total of $9 \mathrm{~mL}$ of fetal blood were withdrawn during the entire study, which is approximately $10 \%$ of fetal blood volume.

For each measurement, blood samples were slowly withdrawn from the fetal axillary artery and superior sagittal sinus, and the maternal femoral artery $(0.3 \mathrm{~mL}$ each vessel $)$ and analyzed for $\mathrm{pH}, \mathrm{Hb}$ concentration, $\mathrm{O}_{2}$ saturation, and blood gases. In addition, arterial blood $(2 \mathrm{~mL})$ was analyzed for cocaine and its metabolites in ewes before and at 5 and $15 \mathrm{~min}$ after cocaine injection, and in fetuses only at $5 \mathrm{~min}$. After blood was sampled, radiolabeled microspheres $(0.3 \mathrm{~mL})$ were injected into the inferior vena cava while reference samples were withdrawn from the axillary artery. All withdrawn blood was immediately replaced with warmed fetal blood obtained from the exchange transfusion procedure.

One baseline measurement was obtained. Then, pure cocaine hydrochloride (Sigma Chemical Co., St. Louis, MO; 2 mg/kg 
Table 1. Systemic responses to $2 \mathrm{mg} / \mathrm{kg}$ maternal cocaine injection in immature fetal sheep

\begin{tabular}{|c|c|c|c|c|}
\hline & \multirow[b]{2}{*}{ Baseline } & \multicolumn{3}{|c|}{ Time after maternal cocaine injection (min) } \\
\hline & & 2 & 5 & 15 \\
\hline MAP (mm Hg) & $39 \pm 1$ & $43 \pm 1$ & $48 \pm 2 *$ & $42 \pm 2$ \\
\hline Heart rate (beats/min) & $206 \pm 4$ & $216 \pm 6$ & $225 \pm 6$ & $234 \pm 9$ \\
\hline Arterial $\mathrm{pH}$ & $7.32 \pm 0.02$ & $7.32 \pm 0.01$ & $7.30 \pm 0.02$ & $7.30 \pm 0.02$ \\
\hline $\mathrm{PaCO}_{2}(\mathrm{kPa})$ & $6.5 \pm 0.13$ & $6.5 \pm 0.13$ & $6.8 \pm 0.13$ & $6.7 \pm 0.13$ \\
\hline $\mathrm{PaO}_{2}(\mathrm{kPa})$ & $2.8 \pm 0.13$ & $2.8 \pm 0.13$ & $2.4 \pm 0.27 *$ & $2.9 \pm 0.13$ \\
\hline Hematocrit, \% & $0.32 \pm 0.01$ & & & $0.31 \pm 0.007$ \\
\hline Hemoglobin $(\mathrm{gm} / \mathrm{L})$ & $91 \pm 2$ & $94 \pm 2$ & $93 \pm 3$ & $92 \pm 2$ \\
\hline Arterial $\mathrm{O}_{2}$ saturation, $\%$ & $62 \pm 2$ & $50 \pm 5^{*}$ & $49 \pm 5^{*}$ & $57 \pm 4$ \\
\hline
\end{tabular}

Values are means \pm SEM; $n=9$ fetal sheep.

$* p<0.05$, compared with baseline.

maternal weight dissolved in $5 \mathrm{~mL}$ of $0.9 \%$ saline) was injected over $10 \mathrm{~s}$ into the maternal jugular vein followed by $5 \mathrm{~mL}$ of $0.9 \%$ saline flush. Measurements were made 2, 5, and $15 \mathrm{~min}$ after cocaine injection.

Data analysis and calculations. CBF was calculated as CBF $=\left(\mathrm{cpm}_{\text {brain }} / \mathrm{cpm}_{\text {ref }}\right) \times 1.03 \mathrm{~mL} / \mathrm{min}$, where $\mathrm{cpm}_{\text {brain }}$ and $\mathrm{cpm}_{\text {ref }}$ represent radioactive counts/min in brain and reference samples, respectively. Other organ blood flows were calculated similarly. Cerebral metabolic rate of $\mathrm{O}_{2}\left(\mathrm{CMRO}_{2}\right)$ was calculated as $\mathrm{CMRO}_{2}=\left(\mathrm{CaO}_{2}-\mathrm{CVO}_{2}\right) \times \mathrm{CBF}$, where $\mathrm{CaO}_{2}$ and $\mathrm{CVO}_{2}$ represent arterial and venous $\mathrm{O}_{2}$ content, respectively. Cerebral $\mathrm{O}_{2}$ delivery (OD) was calculated as $\mathrm{CaO}_{2} \times \mathrm{CBF}$ and cerebral $\mathrm{O}_{2}$ extraction (E) as $\mathrm{CMRO}_{2} \div$ OD. Vascular resistance was calculated as MAP per organ blood flow.

Measurements were calculated and data are reported as mean $\pm S E M$ for all study fetuses. Differences between groups were analyzed by repeated-measures analysis of variance. If the $F$ test was significant, specific differences were sought with the Newman-Keuls test. Significance was considered at $p<$ 0.05 .

\section{RESULTS}

Fetal cardiovascular variables, hematocrit, and arterial blood gases at baseline and in response to maternal cocaine injection are shown in Table 1 . Baseline values are consistent with previous physiologic studies in immature fetal sheep. There were no changes in fetal heart rate, arterial $\mathrm{pH}, \mathrm{PaCO}_{2}, \mathrm{Hb}$, or hematocrit during the study.

Fetal $\mathrm{CBF}, \mathrm{MAP}, \mathrm{CVR}$ and $\mathrm{CaO}_{2}$ at baseline, and in response to maternal cocaine injection are depicted in Figure $1 a-d$ and Tables 2 and 3. There was a $19 \pm 9 \%$ increase in CBF (Fig. $1 a$ and Table 2) at $5 \mathrm{~min}(64 \pm 17$ versus $52 \pm 9 \mathrm{~mL} / 100 \mathrm{~g} / \mathrm{min}$ at baseline). Other regional brain blood flow responses (Table 2) paralleled the changes in $\mathrm{CBF}$ at $5 \mathrm{~min}$ with the greatest percentage increase in blood flow occurring in brainstem $(\uparrow 31$ $\pm 16 \%$ ). Blood flow returned to baseline by $15 \mathrm{~min}$ in each region. Mean arterial blood pressure (Fig. $1 b$ ) increased $(\uparrow 21$ $\pm 6 \%$ ) 5 min after maternal cocaine injection and returned to baseline by $15 \mathrm{~min}$. Cerebrovascular resistance, calculated as CBF/MAP (Fig. $1 c$ and Table 3), increased at $2 \mathrm{~min}$ and returned to baseline at $5 \mathrm{~min}$. There were no changes in calculated vascular resistance in cerebellum or brainstem (Table 3). $\mathrm{CaO}_{2}$ (Fig. 1d) decreased at 2 and $5 \mathrm{~min}$, primarily because of a decrease in arterial $\mathrm{O}_{2}$ saturation, as noted in
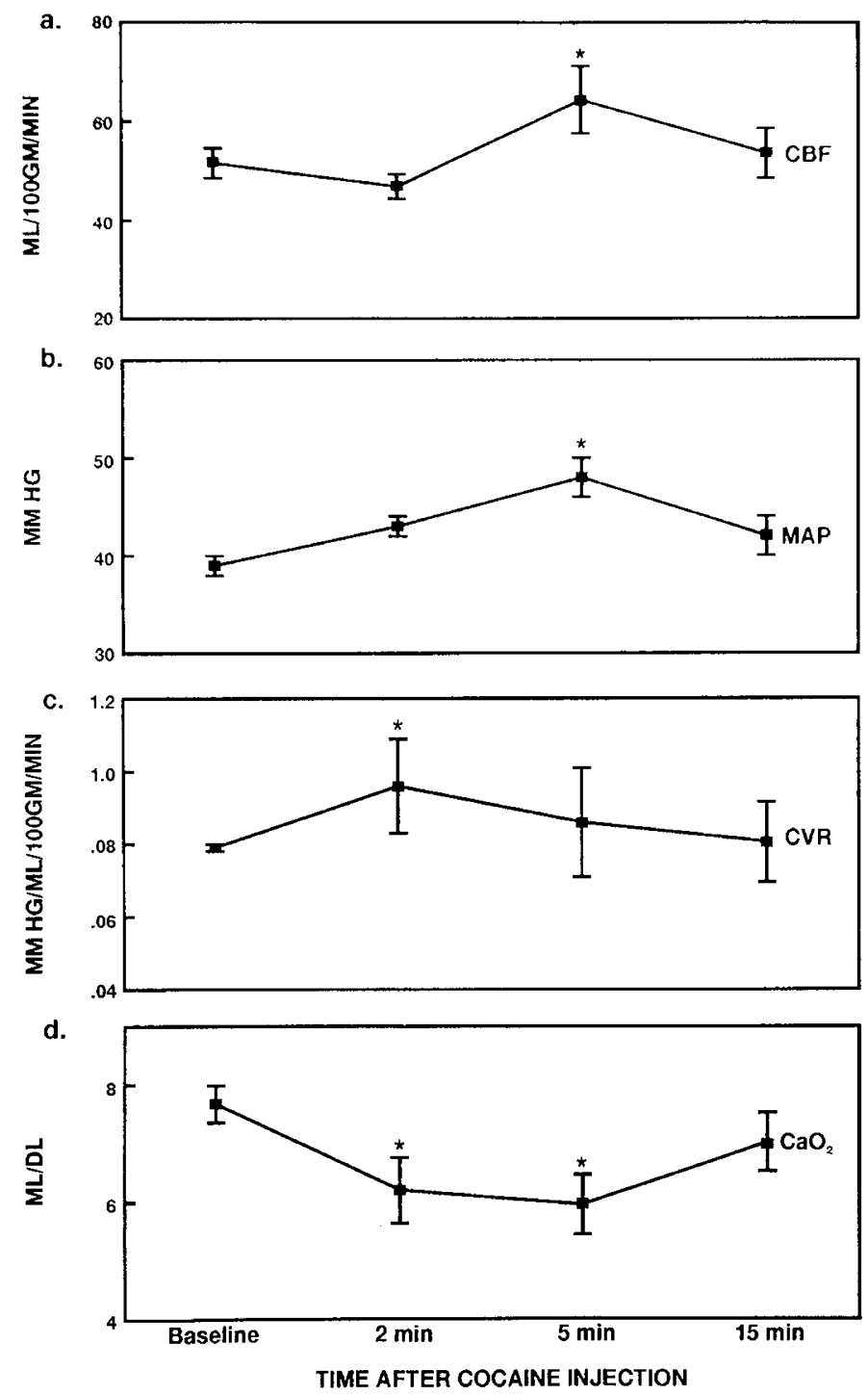

Figure 1. Fetal CBF $(a), \operatorname{MAP}(b), \mathrm{CVR}(c)$, and $\mathrm{CaO}_{2}(d)$ in nine immature fetal sheep (mean $\pm \mathrm{SEM}$ ) at baseline and at 2, 5, and 15 min after maternal cocaine injection $(2 \mathrm{mg} / \mathrm{kg})(1 \mathrm{mM} \mathrm{O} 2=22.4 \mathrm{~mL}) .{ }^{*} p<0.05$ compared with baseline.

Table 1. There was also a small but significant decrease in $\mathrm{PaO}_{2}$ $(\downarrow 16 \pm 5 \%)$ at 5 min. Both $\mathrm{CaO}_{2}$ and $\mathrm{PaO}_{2}$ returned to baseline by $15 \mathrm{~min}$.

Cerebral $\mathrm{O}_{2}$ metabolism data are shown in Table 4. In two of nine animals, there were technical problems with the sagittal 
Table 2. Regional brain blood flow ( $\mathrm{mL} / 100 \mathrm{~g} / \mathrm{min}$ ) responses to $2 \mathrm{mg} / \mathrm{kg}$ maternal cocaine injection in immature fetal sheep

\begin{tabular}{lrccc} 
& & \multicolumn{3}{c}{ Time after maternal cocaine injection (min) } \\
\cline { 3 - 4 } & Baseline & 2 & 5 & 15 \\
\hline Cerebrum & $52 \pm 3$ & $47 \pm 3$ & $64 \pm 7^{*}$ & $54 \pm 5$ \\
Brebellum & $81 \pm 7$ & $83 \pm 8$ & $102 \pm 14^{*}$ & $94 \pm 11$ \\
\hline
\end{tabular}

Values are means \pm SEM; $n=9$ fetal sheep.

$* p<0.05$, compared with baseline.

Table 3. Regional vascular resistance $(\mathrm{mm} \mathrm{Hg} / \mathrm{ml} / 100 \mathrm{~g} / \mathrm{min})$ in response to $2 \mathrm{mg} / \mathrm{kg}$ maternal cocaine injection in immature fetal sheep

\begin{tabular}{lllll}
\hline & & \multicolumn{3}{c}{ Time after maternal cocaine injection (min) } \\
\cline { 3 - 5 } & Baseline & 2 & 5 & 15 \\
\hline Cerebrum & $0.79 \pm 0.1$ & $0.96 \pm 0.13 *$ & $0.86 \pm 0.15$ & $0.81 \pm 0.11$ \\
Cerebellum & $0.48 \pm 0.04$ & $0.53 \pm 0.06$ & $0.52 \pm 0.07$ & $0.45 \pm 0.05$ \\
Brainstem & $0.34 \pm 0.03$ & $0.39 \pm 0.03$ & $0.34 \pm 0.05$ & $0.31 \pm 0.03$ \\
\hline
\end{tabular}

Values are mean $\pm \mathrm{SEM} ; n=9$ fetal sheep.

$* p<0.05$, compared with baseline.

Table 4. Fetal cerebral $\mathrm{O}_{2}$ metabolism before and after maternal cocaine injection

\begin{tabular}{lcccc}
\hline & & \multicolumn{3}{c}{ Time after maternal cocaine injection (min) } \\
\cline { 2 - 4 } & Baseline & 2 & 5 & 15 \\
\hline Arterial $\mathrm{O}_{2}$ content $(\mathrm{mL} / \mathrm{dL})$ & $7.66 \pm 0.32$ & $6.19 \pm 0.56^{*}$ & $5.94 \pm 0.51^{*}$ & $7.01 \pm 0.50$ \\
$\mathrm{O}_{2}$ Consumption $(\mathrm{mL} / 100 \mathrm{~g} / \mathrm{min})$ & $1.19 \pm 0.11$ & $0.86 \pm 0.13$ & $1.20 \pm 0.19$ & $1.42 \pm 0.15$ \\
$\mathrm{O}_{2}$ delivery $(\mathrm{mL} / 100 \mathrm{~g} / \mathrm{min})$ & $3.72 \pm 0.20$ & $2.83 \pm 0.24^{*}$ & $3.32 \pm 0.26$ & $3.60 \pm 0.25$ \\
Fractional $\mathrm{O}_{2}$ extraction & $0.31 \pm 0.02$ & $0.34 \pm 0.05$ & $0.34 \pm 0.04$ & $0.37 \pm 0.02$ \\
\hline
\end{tabular}

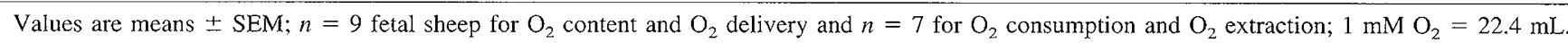

$* p<0.05$, compared with baseline.

sinus catheter; therefore, $n=7$ for $\mathrm{CMRo}_{2}$ and fractional $\mathrm{O}_{2}$ extraction. Cerebral $\mathrm{O}_{2}$ delivery decreased at $2 \mathrm{~min}$, but returned to baseline by $5 \mathrm{~min}$. There were no changes in $\mathrm{CMRo}_{2}$ or fractional $\mathrm{O}_{2}$ extraction throughout the study.

Arterial plasma cocaine and cocaine metabolites (maternal and fetal) are shown in Table 5. Fetal blood was analyzed only at $5 \mathrm{~min}$. Cocaine levels at baseline were zero in maternal blood and were therefore assumed to be zero in fetal blood. At $5 \mathrm{~min}$, cocaine levels were $226 \pm 80 \mathrm{ng} / \mathrm{mL}$ (fetal) and $303 \pm$ $267 \mathrm{ng} / \mathrm{mL}$ (maternal). Cocaine was rapidly metabolized to ecgonine methyl ester in both ewe and fetus, and ecgonine methyl ester levels remained elevated at $15 \mathrm{~min}$. Maternal cocaine levels at $5 \mathrm{~min}$ are approximately $60 \%$ higher than human levels reported $30 \mathrm{~min}$ after a moderate $(40 \mathrm{mg}$ ) cocaine dose (23).

Table 5. Arterial cocaine and cocaine metabolite blood levels $(\mathrm{ng} / \mathrm{mL})$ in immature sheep and their mothers after maternal cocaine injection

\begin{tabular}{|c|c|c|c|}
\hline & \multirow[b]{2}{*}{ Baseline } & \multicolumn{2}{|c|}{$\begin{array}{c}\text { Time after maternal } \\
\text { cocaine } \\
\text { Cocaine injection (min) }\end{array}$} \\
\hline & & 5 & 15 \\
\hline \multicolumn{4}{|l|}{ Fetus } \\
\hline Cocaine & & $225 \pm 27$ & \\
\hline Benzoylecgonine & & $144 \pm 27$ & \\
\hline Ecgonine methyl ester & & $488 \pm 86$ & \\
\hline \multicolumn{4}{|l|}{ Mother } \\
\hline Cocaine & 0 & $303 \pm 89$ & $131 \pm 39$ \\
\hline Benzoylecgonine & 0 & $152 \pm 17$ & $182 \pm 23$ \\
\hline Ecgonine methyl ester & 0 & $786 \pm 61$ & $732 \pm 50$ \\
\hline
\end{tabular}

Values are mean \pm SEM; $n=7$ fetal sheep, $n=9$ mothers.

\section{DISCUSSION}

The major findings of this study are that immature fetal sheep, like mature fetuses, respond to maternal cocaine injection with hypoxemia and hypertension. However, unlike mature fetuses, immature fetuses demonstrate cerebral vasoconstriction at $2 \mathrm{~min}$ with decreased cerebral $\mathrm{O}_{2}$ delivery, and at 5 min no vasodilation is observed in any brain region.

Most studies of the fetal cerebral circulation have been performed in near-term fetal sheep, but the fetal sheep brain is quite mature near term, both structurally and functionally. The 90-d gestation sheep brain is comparable to a 26 -wk gestation human brain (24-27), a gestational age at which approximately $90 \%$ of prematurely born infants in America now survive with excellent neonatal care $(28,29)$. It has thus become important to perform fetal cerebral studies in sheep earlier in gestation to make comparisons of results with other mammalian species. A growing body of literature now suggests that cerebrovascular responses of the developing sheep fetus are indeed uniquely different from responses of more mature fetuses. Immature fetal sheep at 90-d gestation have, for example, significantly lower $\mathrm{CBF}, \mathrm{CMRO}_{2}$, and CMRglu compared with mature fetal sheep $(15,40)$. Although $\mathrm{CO}_{2}$ responses are normal (30), cerebral vasodilatory responses to hypoxemia are blunted (16), cerebral autoregulation in response to intracranial hypertension is poorly developed (31); and cerebrovascular and metabolic responses to acute maternal alcohol intoxication are virtually absent (32). It is therefore not surprising that immature fetal cerebrovascular responses to maternal cocaine would differ from more mature fetuses. 
Fetal systemic and cerebrovascular responses to maternal cocaine injection have been well described in near-term pregnant sheep. Woods et al. (33) reported a $22 \%$ increase in fetal MAP, a $47 \%$ decrease in uterine blood flow and a $21 \%$ decrease in fetal arterial $\mathrm{Po}_{2} 5 \mathrm{~min}$ after a $2 \mathrm{mg} / \mathrm{kg}$ maternal cocaine injection. Moore et al. (34) noted fetal hypertension and decreased uterine blood flow after a $1 \mathrm{mg} / \mathrm{kg}$ injection of cocaine to pregnant ewes. We previously reported a $22 \%$ increase in fetal MAP, a $33 \%$ decrease in fetal $\mathrm{CaO}_{2}$, and vasodilation in some brain regions $5 \mathrm{~min}$ after a $2 \mathrm{mg} / \mathrm{kg}$ maternal cocaine injection near term in sheep. We have also reported cerebral vasodilation after direct cocaine injection in mature fetal sheep and newborn lambs (11, 14). However, other investigators, using different species and methodology, have reported that cocaine constricts cerebral vessels $(7-10)$. The results from the present study suggest that developmental differences in the cerebrovascular responses to cocaine may partially account for some of these conflicting results. More immature vessels, such as those of the 90-d sheep fetus, or the newborn rat or piglet, may respond to cocaine by vasoconstriction, whereas more mature vessels dilate.

The vasoconstriction we observed in all brain regions at 2 min differs significantly from our previous findings in mature fetuses in which we observed no changes in vascular resistance at 2 min. Similar increases in MAP and decreases in $\mathrm{CaO}_{2}$ were observed, thus making it unlikely that differences in fetal systemic responses to maternal cocaine accounted for the different cerebrovascular responses. Furthermore, incomplete development of autoregulation in immature fetuses could not account for this difference because an increase in MAP with impaired autoregulation would have resulted in cerebral vasodilation, not vasoconstriction. Cocaine is a sympathomimetic drug that exerts its direct effects on peripheral blood vessels by enhancing responsivity to catecholamines (35), by blocking the reuptake of norepinephrine from perivascular nerve terminals (36) and by increasing catecholamine output from the adrenal medulla (37). Mechanisms for cocaine's cerebrovascular responses are less well understood, but may depend in part on the ability of cocaine and its metabolites, as well as norepinephrine, to cross the blood-brain barrier. The blood-brain barrier in fetal sheep at $90 \mathrm{~d}$ gestation is well developed (38). However, it is not known what effect hypertension and/or hypoxemia may have on its integrity in immature sheep. If it is disrupted, then one might observe increased brain cocaine and/or norepinephrine levels with consequent vasoconstriction. Alternatively, vascular responses in the immature fetus may reflect unopposed vasoconstriction due to limited vasodilatory capacity. We have previously shown that the CBF response to hypoxemia is attenuated in preterm fetal sheep (16). Since cocaine was associated with a similar decrease in $\mathrm{CaO}_{2}$ at $2 \mathrm{~min}$ in mature and immature fetuses, we could speculate that inadequate release of $\mathrm{O}_{2}$-sensitive vasoactive substances (such as nitric oxide or adenosine) occurred in preterm fetuses, allowing unopposed vasoconstrictive effects of cocaine or norepinephrine. In support of this hypothesis, Northington et al. (39) have recently shown that nitric oxide synthase activity in cortex increases to adult levels after 90-d gestation in fetal sheep.
The transient cerebral vasoconstriction at 2 min could potentially have an adverse effect on the developing brain, particularly if maternal cocaine use occurs in a chronic, repetitive fashion. Cerebral $\mathrm{O}_{2}$ delivery was decreased, albeit for a short period of time, and this could make certain brain regions more vulnerable to hypoxic-ischemic brain injury. Although we were only able to measure $\mathrm{O}_{2}$ consumption by cerebrum (and noted no change), other brain regions could have increased their $\mathrm{O}_{2}$ consumption in response to cocaine or catecholamines and could therefore become vulnerable to decreases in $\mathrm{O}_{2}$ delivery, particularly if such regions are unable to increase their $\mathrm{O}_{2}$ extraction.

The lack of cocaine-induced cerebral vasodilation at $5 \mathrm{~min}$ (compared with baseline, Fig. 1c) also contrasts with our previous findings in mature fetal sheep in which we observed vasodilation in some brain regions. Of note, however, is that although there was no decrease in CVR at 5 min compared with baseline, there was a decrease in CVR from the elevated 2-min measurement (Fig. 1c), suggesting either that cocaine actually had limited vasodilatory effects in immature fetuses or that its vasoconstrictive effect was very transient. In our previous study in near-term fetuses, we were unable to explain cocaine-induced cerebral vasodilation on the basis of coupling to an increase in $\mathrm{CMRO}_{2}$ (there was none) nor solely as a response to hypoxemia. We speculated that it was likely due to the combined effects of fetal cerebral responses to hypoxemia, hypertension (with impaired autoregulation), and to direct or indirect effects of cocaine or its metabolites on fetal cerebral vessels. A subsequent study in which we injected cocaine directly to the fetus supported the hypothesis that cerebral vasodilation is not due solely to fetal hypoxemia but rather is largely a direct or indirect effect of cocaine or its metabolites on cerebral blood vessels, independent of the uteroplacental circulation (14). Because we observed less hypoxemia at $5 \mathrm{~min}$ in the immature fetuses than we had observed in the mature fetuses, this could explain in part the absence of cerebral vasodilation at $5 \mathrm{~min}$ (compared with baseline). Less significant hypoxemia in the immature fetuses could have occurred because of the multicotyledonary sheep placenta which has a larger surface area relative to fetal size and blood volume earlier in gestation and consequently may render the preterm fetus potentially less vulnerable to uteroplacental vasoconstriction from maternal cocaine than the term fetus, with consequently less fetal hypoxemia. Another explanation for the absence of cocaine-induced vasodilation is the blunted vasodilatory response to hypoxemia by immature fetuses which we have previously reported, resulting in decreased $\mathrm{O}_{2}$ delivery. This is not due to undeveloped vasoreactivity to adenosine (41), but rather reflects either immature regulatory mechanisms or an inability of cerebral vessels to respond to the usual stimuli (16). Finally, an increase in fetal $\mathrm{P}_{50}$ secondary to maternal blood transfusion could have altered cerebrovascular responses to cocaine and/or to hypoxemia. However, our method of maternalfetal exchange transfusion before study to provide blood for replacement was successful in preventing any changes in fetal $\mathrm{P}_{50}$ (estimated using oxygen saturations, a Hill coefficient of 2.58 and a Bohr factor of 0.44 corrected to $\mathrm{pH} 7.40$ ). Therefore, alterations in fetal oxygen affinity could not explain the absence of cocaineinduced cerebral vasodilation. 
Although we did not observe cerebral vasodilation at $5 \mathrm{~min}$ in immature fetuses, $\mathrm{CBF}$ increased enough to maintain cerebral $\mathrm{O}_{2}$ delivery, unlike the response at $2 \mathrm{~min}$. However, an acute increase in CBF may be detrimental to immature brain, particularly when accompanied by acute changes in blood pressure. In preterm infants, acute increases in blood pressure, abrupt changes in cerebral blood flow velocity and acute volume expansion are associated with intracranial hemorrhages $(42,43)$.

Fetal and maternal cocaine levels were similar to those reported in our previous studies using a $2 \mathrm{mg} / \mathrm{kg}$ maternal cocaine injection near-term (12). We were limited to a single fetal cocaine level because of the volume of blood required for an accurate measurement $(2 \mathrm{~mL})$ and the limitations in donor fetal blood that we had. We chose a fetal measurement at $5 \mathrm{~min}$ because that is the time at which the most significant fetal responses were seen in our near-term fetal studies. There were no significant differences between fetal and maternal cocaine levels at $5 \mathrm{~min}$, nor were there differences noted in cocaine levels between the present study and our previous study in mature fetuses. Maternal cocaine levels are presumably higher before $5 \mathrm{~min}$ as there was evidence of rapid metabolism to ecgonine methyl ester by $5 \mathrm{~min}$. Metabolism of cocaine in sheep is different from in humans; it is more rapid, and ecgonine methyl ester is a major sheep metabolite whereas benzoylecgonine, a major human metabolite, is not.

In summary, immature fetuses respond differently to maternal cocaine injection than mature fetuses because despite transient hypoxemia, they demonstrate initial cerebral vasoconstriction, with decreased cerebral $\mathrm{O}_{2}$ delivery, and no subsequent cerebral vasodilation. Developmental differences in fetal responses to maternal cocaine may be due to differences in integrity of the blood-brain barrier, different levels of or responses to hypoxemia or to differences in vascular responses to cocaine, its metabolites, or to norepinephrine.

Acknowledgments. The authors gratefully acknowledge the excellent technical assistance of Debby Flock, the secretarial support of Lorretta Hook and Patricia Williams, and the services of Dr. Bruce Goldberger and the Neonatal Center for Forensic Sciences who measured blood levels of cocaine and its metabolites.

\section{REFERENCES}

1. Vega WA, Kolody B, Hwang J, Noble A 1993 Prevalence and magnitude of perinatal substance exposures in California. N Engl J Med 329:850-854

2. Ostrea EM, Brady M, Gause S, Reynolds AL, Stevens M 1992 Drug screening of newborns by meconium analysis: a large-scale, prospective, epidemiologic study. Pediatr 80:107-113

3. Singer LT, Yamashita TS, Hawkins S, Cairns D, Baley J and Kliegman R 1994 Increased incidence of intraventricular hemorrhage and developmental delay in cocaine-exposed, very low birth weight infants. J Pediatr 124:765-771

4. Volpe JJ 1992 Effect of cocaine use on the fetus. N Engl J Med 327:399-407

5. Chasnoff IJ, Bussey ME, Savich ME, Stack CM 1986 Perinatal cerebral infarction and maternal cocaine use. J Pediatr 108:456-459

6. Heier LA, Carpanzano CR, Mast J, Brill PW, Winchester P, Deck MDF 1991 Maternal cocaine abuse: the spectrum of radiologic abnormalities in the neonatal CNS. AJNR 12:951-956

7. Madden JA, Powers RH 1990 Effect of cocaine and cocaine metabolites on cerebral arteries in vitro. Life Sci 47:1109-1114

8. Covert RF, Schreiber MD, Tebbett IR, Torgerson LJ 1994 Hemodynamic and cerebral blood flow effects of cocaine, cocaethylene and benzoylecgonine in conscious and anesthetized fetal lambs. J Pharmacol Exp Ther 270:118-126

9. Kurth CD, Monitto C, Albuquerque ML, Fever P, Anday E, Shaw L 1993 Cocaine and its metabolites constrict cerebral arterioles in newborn pigs. J Pharmacol Exp Ther 265:587-591
10. Schreiber MD, Madden JA, Covert RF, Torgerson LJ 1994 Effects of cocaine, benzoylecgonine, and cocaine metabolites on cannulated pressurized fetal sheep cerebral arteries. J AppI Physiol 77:834-839

11. O'Brien TP, Gleason CA, Jones MD Jr, Cone EJ, London ED, Traystman RJ 1994 Cerebral responses to single and multiple cocaine injections in newborn sheep. Pediatr Res 35:339-343

12. Gleason CA, Iida H, O'Brien TP, Jones MD Jr, Cone ED, Traystman RJ 1993. Fetal responses to acute maternal cocaine injection in sheep. Am J Physiol 265:H9-H14

13. Dohi S, Jones MD Jr, Hudak ML, Traystman RJ 1990 Effects of cocaine on pial arterioles in cats. Stroke 21:1710-1714

14. Iida H, Gleason CA, O'Brien TP, Traystman RJ 1994 Fetal responses to acute fetal cocaine injection in sheep. Am J Physiol 267: H1968-H1975

15. Gleason CA, Hamm C, Jones Jr MD 1989 Cerebral blood flow, oxygenation, and carbohydrate metabolism in immature fetal sheep in utero. Am J Physiol 256:R1264R1268

16. Gleason CA, Hamm C, Jones Jr MD 1990 Effect of acute hypoxemia on brain blood flow and oxygen metabolism in immature fetal sheep. Am J Physiol 258:H1064H1069

17. Kliegman RM, Madura D, Kiwi R, Eisenberg I, Yamashita $T 1994$ Relation of maternal cocaine use to the risks of prematurity and low birth weight. J Pediatr 124:751-756

18. Townsend RR, Laing FC, Jeffrey RB Jr 1988 Placental abruption associated with cocaine abuse. AJR 150:1339-1340

19. Slutsker L 1992 Risks associated with cocaine use during pregnancy. Obstet Gynecol 79:778-789

20. Bateman DA, Ng SKC, Hansen CA, Heagarty MC 1993 The effects of intrauterine cocaine exposure in newborns. Am J Public Health 83:190-193

21. Heymann MA, Payne BD, Hoffman JIE Rudolph AM. Blood flow measurements with radionuclide-labeled particles. Prog Cardiovasc Dis 20:55-77

22. Cone EJ, Hillsgrove M, Darwin WD 1994 Simultaneous measurement of cocaine, cocaethylene, their metabolites, and "crack" pyrolysis products by gas chromoatography-mass spectrometry. Clin Chem 40:1299-1305

23. London ED, Cascella NG, Wong DF, Phillips RL, Dannals RF, Links JM, Herning R, Grayson R, Jaffe JH, Wagner HN Jr 1990 Cocaine-induced reduction of glucose utilization in human brain. Arch Gen Psychiatry 47:567-574

24. Astrom, K-E 1967 On the early development of the isocortex in fetal sheep. Prog Brain Res 26:1-59

25. Bernhard CG, Kolmodin GM, Meyerson BA 1967 On the prenatal development of function and structure in the somesthetic cortex of the sheep. Prog Brain Res 26:60 -77

26. Romanes GJ 1947 The prenatal medullation of the sheep's nervous system. J Anat $81: 65-81$

27. Reynolds ML, Evans CAN, Reynolds EOR, Saunders NR, Durbin GM, Wigglesworth JS 1989 Intracranial hemorrhage. Early Hum Dev 3:163-186

28. Hack M, Horbar JD, Malloy MH, Tyson JE, Wright E, Wright L 1991 Very low birth weight outcomes of the National Institute of Child Health and Human Development neonatal network. Pediatrics 87:587-589

29. Allen MC, Donohue PK, Dusman AE 1993 The limit of viability - Neonatal outcome of infants born at 22 to 25 weeks' gestation. N Engl $\mathbf{J}$ Med 329:1597-1601

30. Helou SM, Hudak ML, Jones MD Jr 1991 Cerebral blood flow responses to hypercapnia in the immature fetal sheep. Am J Physiol 261:H1366-H1379

31. Helou SM, Koehler RC, Gleason CA, Jones MD Jr, Traystman RJ 1994 Cerebrovascular autoregulation during fetal development in sheep. Am J Physiol 266:H1069H1074

32. Gleason CA, Hotchkiss KJ 1992 Cerebral responses to acute maternal alcohol intoxication in immature fetal sheep. Pediatr Res 31:645-648

33. Woods JR, Plessinger MA, Clark KE 1987 Effect of cocaine on uterine blood flow and fetal oxygenation. JAMA 257:957-961

34. Moore TR, Sorg J, Miller L, Key TCV, Resnick R 1986 Hemodynamic effects of intravenous cocaine on the pregnant ewes and fetus. Am J Obstet Gynecol 155:883888

35. Furchgott RF, Kirpekar SM, Rickar M, Schwab A 1963 Actions and interactions of norepinephrine, tryamine and cocaine on aortic strips of rabbit and left atria of guinea pig and cat. 3 Pharmacol Exp Ther 142:39-58

36. Ritchie JM, NM Greene 1985 Local anesthesia. In: Gilman LS, Goodman LS, Rall TW, Murad F (eds) The Pharmacological Basis of Therapeutics. Macmillan, New York, pp 302-321

37. Chieuch CC, Kopin IJ 1978 Centrally mediated release by cocaine of endogenous epinephrine and norepinephrine from the sympathoadrenal medullary system of unanesthetized rats. J Pharmacol Exp Ther 205:148-154

38. Evans CAN, Reynolds JM, Reynolds ML, Saunders NR, Segal MB. 1974 The development of a blood-brain barrier mechanism in foetal sheep. J Physiol 238:371386

39. Northington FJ, Tobin JR, Koehler RC, Traystman RJ 1994 Ontogeny of nitric oxide synthase (NOS) activity from mid-gestation to adulthood. Pediatr Res 35:384A

40. Jones MD Jr, Sheldon RE, Peeters LL, Makowski EL Meschia G 1978 Regulation of cerebral blood flow in the ovine fetus. Am J Physiol 235:H162-H166

41. Kurth CD, Wagerle LC 1992 Cerebrovascular reactivity to adenosine analogues in 0.6-0.7 gestation and near-term fetal sheep. Am J Physiol 262:H1338-H1342

42. Funato M, Tamai H, Noma K, Kurita T, Yoshioka Y Shimada S. 1992 Clinical events in association with timing of intraventricular hemorrhage in preterm infants. J Pediatr 121:614-619

43. Perry EH, Bada HS, Ray JD, Korones SB, Arheart K, Magill HL 1990 Blood pressure increases, birth-weight dependent stability boundary, and intraventricular hemorrhage. Pediatrics 85:727-732 